\title{
Allergic reaction in the use of primacaine adrenaline
}

\author{
Hui Xia He, Lin Feng, Hong Chen Liu \\ Department of Stomatology, Institute of Dental Research, General Hospital of Chinese People's Liberation Army, Beijing, China \\ Postep Derm Alergol 2015; XXXII, 2: 134-136 \\ DOI: $10.5114 /$ pdia.2015.48035
}

Articaine hydrochloride and adrenaline injection, also known as primacaine adrenaline, is an aqueous solution of $4 \%$ adrenaline with 1 : 100,000 adrenaline [1]. Its advantages include fast diffusion through tissues, low dosage, strong local anesthesia efficacy, rapid onset, long duration, being less toxic than lidocaine and avoiding conduction anesthesia complications, like hematoma, infection and nerve injury. It is suitable for local infiltration anesthesia [2] and works quite well clinically in buccal infiltration anesthesia and conduction anesthesia in surgical procedures of osteotomy and mucosal incision [3]. The associated side effects of articaine and adrenaline injection are minor and will disappear after the therapy, and they include neuropathy, nervousness, drowsiness, tremors, anxiety, excessive wordiness, headache, nausea and tinnitus. There have been some reports about allergic reactions caused by administration of articaine and adrenaline injection, of which anaphylaxis is rare. The mechanism of the allergic reaction is still unclear and needs further investigation. Anaphylaxis caused by drugs is the most serious type I hypersensitivity, and may cause death if not treated on time $[4,5]$.

In this paper, we present a case report of a severe allergic reaction after using the articaine and adrenaline injection, which suggests that close monitoring for allergic reactions is necessary for patients who are first exposed to or specifically susceptible to articaine.

A 65-year-old male patient reported feeling pain in the right upper back tooth for 3 days. The pain occurred at night 3 days before and became more severe over the 3-day period.

The symptom onset appeared 3 days before. The patient felt a sudden sharp pain at intervals in the right upper back tooth when exposed to hot or cold temperature. He took some painkiller orally for relief. The night before seeing the doctor, the pain became intolerable and the oral painkiller relieved the pain only slightly.
The patient had a past medical history of diabetes, hypertension and lumbar disc protrusion. He denied any history of allergy to food or drugs and had no history of administration of anesthesia agents and injuries. He has not taken any medicines recently.

Physical examination revealed a blood pressure of $140 / 88 \mathrm{~mm} \mathrm{Hg}(1 \mathrm{~mm} \mathrm{Hg}=0.133 \mathrm{kPa})$ and pulse of $72 \mathrm{bpm}$. The patient was conscious and alert. He had a heavy complexion but stable vital signs and responded well to questions. The blood test done 2 weeks before revealed a glucose level of $5.6 \mathrm{mmol} / \mathrm{l}$, triglycerides of $1.25 \mathrm{mmol} / \mathrm{l}$, LDL (bad) cholesterol of $2.23 \mathrm{mmol} / \mathrm{l}$ and apolipoprotein of $0.78 \mathrm{~g} / \mathrm{l}$. Electrocardiography (ECG) appearance was almost normal.

Intraoral examination revealed pulpitis (acute) of tooth 16 and periodontitis.

Open medullary decompression was performed under local anesthesia of tooth 16 . Root canal therapy was planned. After conventional cleaning of the buccal side of the right upper back tooth with alcohol and povidone-iodine, and palatal periodontal anesthesia, local filtration anesthesia with $1.7 \mathrm{ml}$ of articaine hydrochloride and adrenaline injection (Laboratoire Pierre Rolland) was performed. The patient appeared normally upon the administration of $0.5 \mathrm{ml}$ injection. However, $5 \mathrm{~min}$ later, the patient complained of discomforts, chest distress, weak breathing, palpitation and dizziness. The injection was then stopped and the patient was referred to emergency treatment.

The patient was told to lie on one side and given oxygen. The patient was referred to the dermatologist and monitored using ECG. Blood pressure was 150/90 mm Hg. Pulse rate was $88 \mathrm{bpm}$. Breathing was 25 breaths per minute and the heart rate was $90 \mathrm{bpm}$. Ten minutes later, local redness appeared on the face, ears and neck. Erythema occurred scaly with uniform color, irregular morphologic appearance and bumps on the skin, followed by an itchy, painless papule. Initially, erythema was mainly

Address for correspondence: Lin Feng, Department of Stomatology, Institute of Dental Research, General Hospital of Chinese People's Liberation Army, Beiling Fu Xing Lu 28, 100853 Beijing, China, phone: +86 13810004701, e-mail: xiahuih-203@163.com Received: 26.05.2014, accepted: 8.07.2014. 

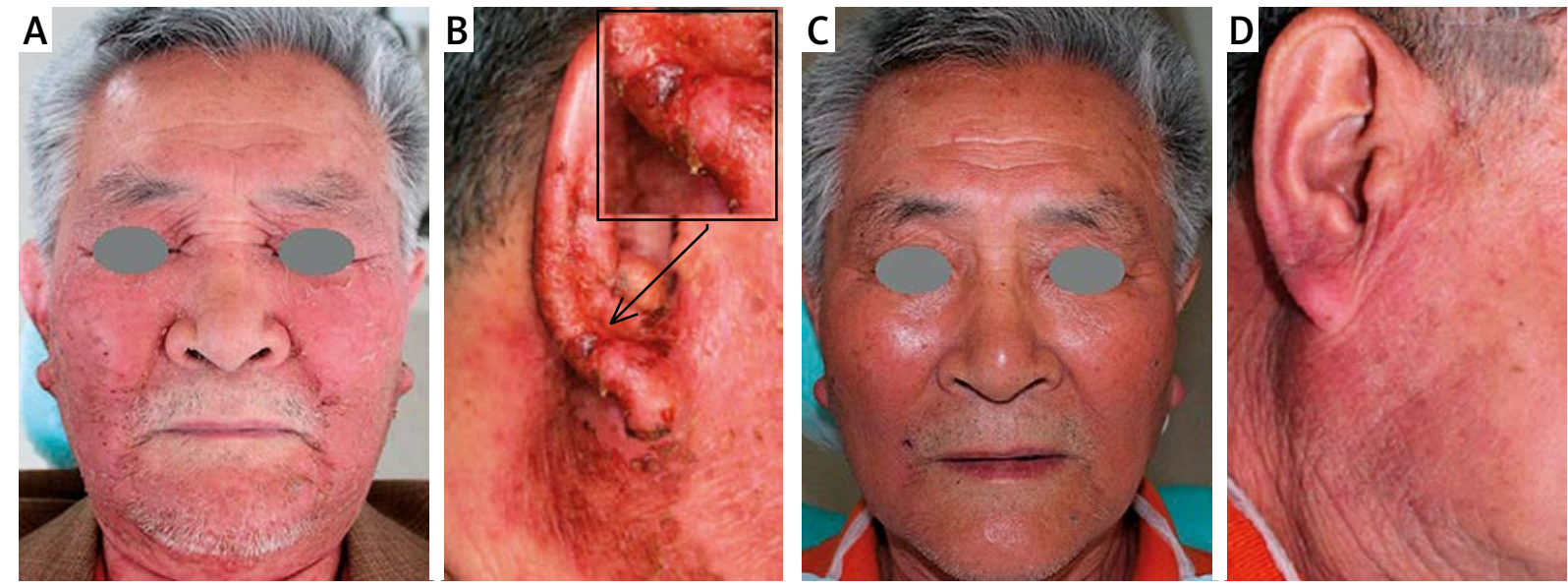

Figure 1. After infection (A, B) and after 1 week (C, D)

located on the cheeks and later it spread behind the ear and ran down the front of the neck and chest. The dermatologist suggested an allergy to primacaine adrenaline. The patient was given $2 \mathrm{ml}$ of betamethasone and referred to allergy testing for confirmation. $1.5 \mathrm{~h}$ later, symptoms resolved slightly and discomforts like chest distress, weak breathing and dizziness diminished. All the discomforts resolved completely in the evening on the same day. The next day, erythema reduced and crust formation started, resembling a false membrane, with a few bleeding spots. After 3 days, erythema resolved completely and a scab formed. Brown crusts and exfoliation were still present behind ears. The allergy testing later confirmed that the patient was sensitive to primacaine adrenaline, sulphonamide and shrimp products.

The patient was then informed about the prevention and treatment and prescribed terfenadine tablets $(60 \mathrm{mg}$ each time, twice a day). He took the tablets orally for 3 days. The symptoms resolved completely (Figure 1 ).

It has been proved that articaine can be catabolized or hydrolyzed into articainic acid (as shown in Figure 2), of which $25 \%$ will be glucuronidated and then excreted by kidneys. Apart from epidural anesthesia, the research of pharmacokinetics of articaine can also be carried out under axillary brachial plexus anesthesia, intravenous regional anesthesia (IVRA) and tooth pulp anesthesia.

Articaine is the most widely used local anesthetic in dentistry in European countries. The skin test is usually unnecessary [5]. In approximate $90 \%$ of cases, a dosage of $60-80 \mathrm{mg}$ of articaine (4\%) with $5 \mathrm{mg} / \mathrm{ml}$ of adrenaline is administered [6]. Compared with other local anesthetics, articaine can diffuse more easily through soft tissue and bones. The risk of systemic toxicity seems to be rare.

With an overdose or inadvertent intravascular administration of articaine, patients might show symptoms like sweating, tachycardia, breathing difficulty and flushing on the face [7]. If the patient is allergic to anesthesia agents, he might suffer anaphylaxis [8]. Sodium metabisulfite, the other constituent in the injection other than
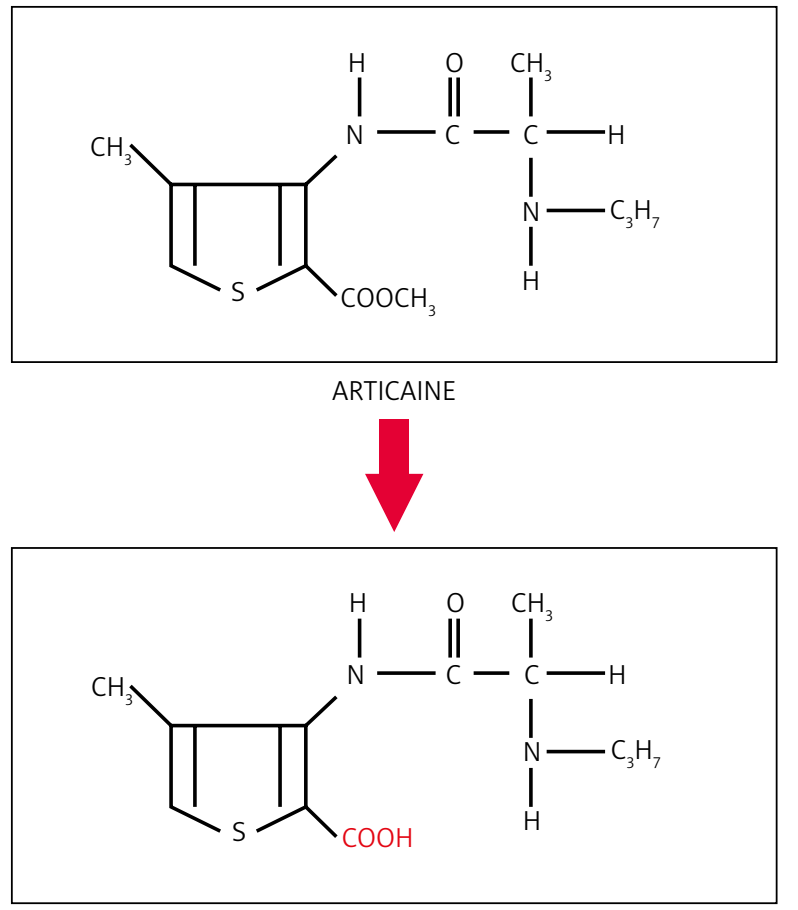

ARTICAINIC ACID
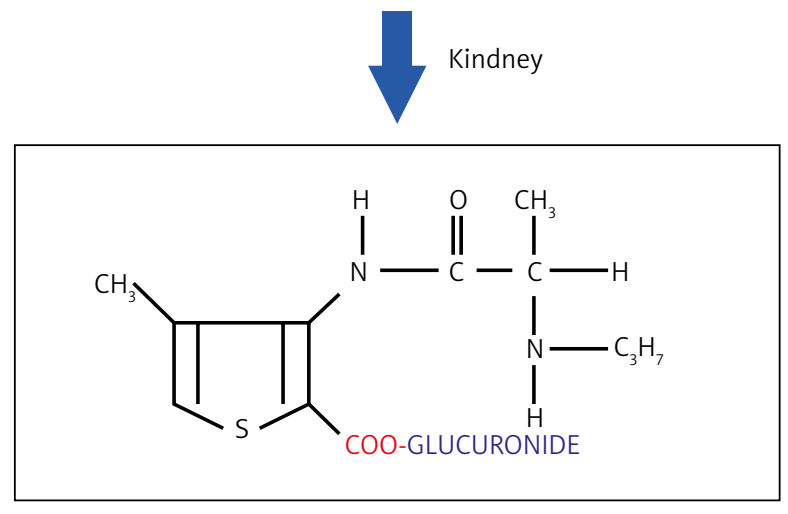

ARTICAINIC ACID GLUCURONIDE

Figure 2. Articaine and its metabolites. Glucuronide is synthesized in kidneys 
the drug itself, functioning as an antioxidant to maintain or increase the stability and utilization of the active ingredient, may increase the possibility of potential adverse reactions. Very few cases of adverse reactions in the use of articaine with an adrenaline injection are recorded in the literature, although the instruction reads "The product contains sodium metabisulfite which may cause or exacerbate allergic symptoms. Patients who are highly suspected of local anesthesia allergy should be referred to a trial with a small dosage (5-10\%) first" $[9,10]$.

As showed by this case report, an articaine injection can result in a very serious adverse reaction although its allergic reaction is rare. This case report also suggests that a skin test before administering articaine is necessary for patients who are exposed to it for the first time and have no history of administration of anesthesia agents.

\section{Acknowledgments}

Natural Science Foundation of China (No. 81070833 j31240049). Military Medical Research 'The Twelfth FiveYear' Project (CWS11J116).

\section{Conflict of interest}

The authors declare no conflict of interest.

\section{References}

1. Semenikhin AA, Din KE. Prolonged epidural analgesia with ultracaine for labor pain relief. Anesteziol Reanimatol 2001; 2: 28-30.

2. Kaukinen S, Eerola R, Eerola M, Kaukinen L. Comparison of articaine and lidocaine in spinal anaesthesia. Ann Clin Res 1978; 10: 191-4.

3. Kozlov SP, Svetlov VA, Lukianov MV. Pharmacology of local anesthetics and clinical aspects of segmentalblocking. II Spinal Anesthesia. Anesteziol Reanimatol 1998; 5: 37-42.

4. Oertel R, Rahn R, Kirch W. Clinical pharmacokinetics of articaine. Clin Pharmacokinet 1997; 33: 417-25.

5. Haas DA, Lennon D. Local anesthetic use by dentists in Ontario. J Can Dent Assoc 1995; 61: 297-304.

6. Malamed SF, Gagnon S, Leblanc D. Articaine hydrochloride: a study of the safety of a new local anesthetic. J Am Dent Assoc 2001; 132: 177-85.

7. Leuschner J, Leblanc D. Studies on the toxicological profile of the local anaesthetic articaine. Arzneimittelforschung 1999; 49: 126-32.

8. MacColl S, Young ER. An allergic reaction following injection of local anesthetic: a case report. J Can Dent Assoc 1989, 55: 981-4.

9. Gall H, Kaufmann R \& Kalveram CM. Adverse reactions to local anesthetics: analysis of 197 cases. J Allergy Clin Immunol 1996; 97: 933-7.

10. Malanin K, Kalimo K. Hypersensitivity to the local anesthetic articaine hydrochloride. Anesth Prog 1995; 42: 144-5. 